\title{
University Students' Perceptions of Videotaping as a Teaching Tool in a Public Speaking Course
}

\author{
Latifa El Mortaji, PhD \\ Al Akhawayn University in Ifrane, Morocco
}

Doi: 10.19044/esj.2018.v14n8p102 URL:http://dx.doi.org/10.19044/esj.2018.v14n8p102

\begin{abstract}
The purpose of this study was to investigate the effect of videotaping on college students' public speaking skills development in English as a Foreign Language (EFL) from the learners' perspective. Twenty Moroccan freshmen students majoring in Engineering, Business, and Humanities at $\mathrm{Al}$ Akhawayn University in Ifrane, Morocco, participated in the study. Using 60 videotaped extemporaneous speeches, pre and post-videotaping surveys together with self-reflection essays, the researcher reports on students' perceptions of and attitudes towards the effectiveness of videotaping on their public speaking competence development. Results revealed that the students' public speaking skills improved over the course of a semester in terms of content, followed by non-verbal communication, verbal communication, organization, and language. In line with some previous research, this study confirms that a combination of videotaping and self-reflection has a major effect on improving students' public speaking skills, developing confidence of EFL learners, and fostering independent learning.
\end{abstract}

Keywords: Perception, attitude, teaching tool, videotaping, public speaking, EFL

\section{Introduction}

Technology has been integrated in college classrooms in many transformative ways (Boling, 2008). Many educators use technology for support and to improve learning opportunities for students. Videotaping, in particular, has been used for the longest time as an effective tool to improve student learning and assessment. As today's teachers and students are native consumers of video content on digital platforms and social media, as well as natural producers of video recordings using smartphones, it is expected that the use of videotaping in the classroom no longer poses a major obstacle, and that the processes of recording, viewing, and annotating recordings are much easier, opening up room for an objective assessment of the use of video 
recording throughout student learning stages. It is becoming much easier for teachers to post and share recordings of their in-class student performance for further out of class peer reviewing and interaction, leading to improved student engagement. It is therefore legitimate to re-examine the impact of in-class video recording on class objectives' attainment, especially from the students' perspective, now that a higher engagement in the learning process (including their own assessment) can be secured inside and outside the classroom.

In order to understand and highlight the importance and effectiveness of videotaping in the classroom for skill development, there is a need to cover the history of using video recording as a teaching tool, sometimes in combination with other strategies such as feedback.

Ever since its development in 1951, video-tape recording has been used for instructional and professional purposes (Ginsburg, 1956). It was particularly used as a skill development tool in various professional fields, such as teaching, physio-therapy, nursing, and medicine. For instance, Maloney, Paynter, Storr, \& Morgan (2013) used self-video in order to assess undergraduate physio-therapy students' clinical performances. The students uploaded videos of their performances on an online platform and received feedback from tutors online. Students deemed that using videos helped them by "supporting their learning" (p. 326). The authors concluded that the advantages of this method consisted in increasing feedback opportunities for the student, the archiving of students' skills, as well as the "decentralization" of learning from the university (p.326). Video recording has also been used in order to assess the feedback delivery capabilities of students training to become teachers (Ramos et al., 2015), as well as to teach surgical operations (Nair et al., 2015), and to develop teachers' usage of "praise" (Pinter et al., 2015).

Through meta-analysis, it was proven that using video recording in professional training contributes to improving verbal and non-verbal features of communication in various professional situations (Fukkink et al., 2011, p. 56). An example would be the use of a combination of visual (video) and verbal feedback in order to assess medical students' communication skills. This method proved to be more effective than the reception of verbal feedback alone (Ozcakar et al., 2009, p. 474). Another example is the study conducted by Mills and Pace (1989) in which they evaluated students' learning of communication skills using three methods separately: practice alone, video recording with instructor feedback, and a combination of video-taping, instructor feedback, and practice. In their conclusion, the authors encouraged the combination of the three methods. 


\section{Literature Review}

\section{Video Taping in the Public Speaking Classroom}

Many scholars have conducted research to assess the usefulness of videotaping in public speaking classes (Frandsen, Larson, \& Knapp, 1968; Diehl, Breen, \& Larson, 1970; McCroskey \& Lashbrook, 1970; Porter \& King, 1972; Mulac, 1974). While some of these studies were exploratory in nature, others specifically investigated the effect of videotaping, sometimes in combination with other techniques such as feedback, on students' apprehension or communication competence in the basic public speaking course. One of the earliest studies was conducted by Woolley (1968) who observed that the students who watched their performances tended to be "more attentive to appearance of themselves, to their facial expressions, movements, gestures, than they were to the sound of their voices" (as cited in Daniel, 1983, p. 3). In addition, Woolley stated that some students showed surprise at their early recordings, embarrassment at their errors, and usually humility more often than pride, even when their work was impeccable. Quigley and Nyquist (1992) described video-taping in public speaking classes as a key to many learning opportunities: to embrace the role of a spectator, to recognize certain skills, to obtain feedback simultaneously with the speech, and to compare different performances. In fact, videotaping involves much more than that. In a subsequent study, Bourhis and Allen (1998) analyzed 12 manuscripts dated from 1969 to 1984 in which various characteristics related to using videotaping in Public Speaking classrooms were studied, including speech content, student attainment of public speaking skills, student "performance on objective tests", and student outlooks on public speaking as a course. The researchers concluded that the use of videotaping in the public speaking classroom leads not only to better proficiency in public speaking, but also to a more positive outlook of students towards the course. Overall, they deemed that in general, the use of video-recording in the public speaking classroom is "justified." (p. 259).

To further understand the effectiveness of videotaping as a pedagogical tool in the public speaking classroom, Guo (2013) compared the overall performances of two groups of graduate teaching- students, with only one group having access to the video recording of previous presentations. Data was collected through student self-valuation and reflection with or without access to the recording. The results showed that video recording helped the graduates improve verbal (speed, volume, intonation, articulation) and nonverbal communication (appearance, facial expression, body language, gestures, and eye contact), organization of the content, and the students' interaction with the audience during the presentation. Similarly, in an English as a Second Language speech classroom, the use of video tapes combined with feedback and video analysis in the form of a reflection paper improved 
students' speech making skills, and rendered their experience more enriching (Wilhelm, 2014, p. 5).

However, even though the use of videotaping in Public Speaking classrooms has been proven to assist students in developing their speech and presentation skills, it has been reported that this technology can have some negative effects too. Daniel (1983) states that by watching their performances, some students find a confirmation of negative ideas about themselves (p. 10). This may be attributed to Woolley's finding (1960) that watching their performances draws the students' attention to their appearance more than to their voices. Similar results were found in a more recent study conducted by Do and Dang (2014). The usage of video recording rendered the students' learning progression more complex, as they didn't know how to handle the camera nor did they have access to computers to review their performances (p.38). In addition, the video equipment distracted the presenters and put them under great deal of stress and dread. Hinton \& Kramer (1998) also found that video-recording student performances did not progress students' public speaking skills. In fact, it affected negatively the speeches of students with moderate to high levels of apprehension (as cited in Thu and Tu, 2012).

While most studies were based on video analysis combined with observation, and sometimes surveys, some researchers used students' perceptions in the analysis of their data. This is the case of Jensen Karla Kay \& Harris Vinnie (1999) who investigated the benefits of using public speaking portfolio (journal writing, speech process log, peer evaluation, teacher evaluation, and videotaped speeches) as a pedagogical tool from the students' perspective. When analyzing students' perceptions of the effectiveness of the portfolio, the researchers found that an average of (4.32) of the students said that "viewing the videotapes was the most helpful component of the portfolio and was seen as a way of identifying specific areas needing improvement" ( $p$. 222).

The literature review revealed that research on videotaping as a pedagogical tool in the public speaking classroom yielded mixed findings, highlighting positive and negative impact on Public Speaking learning in terms of (i) the students' attitude towards the technology, (ii) the students' learning and public speaking skills progression, and (iii) students' apprehension. In the current study, the researcher intends to get a deep insight into the topic under investigation from the EFL learners' perspective. Specifically, the researcher will focus on two main aspects of the use of videotaping in the classroom.

\section{Research Questions}

The aim of this research is to investigate the students' attitudes towards videotaping their speeches, and their perceived improvement in public 
speaking skills as a result of recorded speeches. To this end, the following research questions are addressed:

RQ1. What is the students' attitude towards videotaping their speeches before and after delivering the first speech?

RQ2. What is the students' perception of videotaping as a teaching tool for developing public speaking skills?

\section{Methodology \\ Participants}

Twenty freshmen students aged 18 to 20 enrolled in a Public Speaking course (COM1301) at Al Akhawayn University in Ifrane (AUI), Morocco, were randomly selected to participate in the study. This course is a common core that all AUI students across different disciplines are required to take to improve their communication skills and, therefore, succeed in their academic career, as it is clearly stated in the intended learning outcome of university programs.

\section{Data Collection}

The researcher used three methods to collect data: videotaped speeches, a pre and post videotaping survey, and a self-reflective essay. It is worth noting here that in addition to the videotaped speeches and reflection essays, the participants received teacher feedback after each delivery, but this study does not report on feedback and focuses more on the use of videotaping in the classroom and to what extent it is effective from the learners' perspective.

\section{Videotaped speeches}

During the semester, students were required to prepare three extemporaneous speeches, i.e. self-introduction, informative, and persuasive, that they carefully prepared and rehearsed before the final delivery in the classroom. The professor videotaped the students' speeches using a professional camera provided by the School of Humanities and Social Sciences. After completion of the students' speech delivery, in the following class session the professor provided every student speaker with a copy of her/his speech for personal retention. They were required to watch their performances and identify their strengths and weaknesses.

\section{The survey}

A survey was administered in Week 1 to get insight into the students' feelings and attitudes towards videotaping them in the classroom while delivering their first speech in front of an audience (i.e. classmates). The same survey was administered a second time in Week 4 after the students had 
delivered speech\#1 which was videotaped in class. The aim of the pre and post videotaping survey (appendix) was to compare the students' feelings, attitudes, and reactions before and after videotaping and watching their first speech, to see if there was any change, and highlight the reasons behind this change from the students' perspective.

\section{The reflective essay}

In addition to the survey, the students were required to submit a reflective essay in week 14 whereby they would reflect on their public speaking experience, and do self-assessment of their public speaking skills development across the three speeches. In this process, the students were required to watch their three videotaped speeches, one at a time throughout the semester, do their own assessment of their performance after watching the video, identify their strengths and focus on setting goals to improve areas of weaknesses for their next speech. In the final reflection essay they gave examples of skills and behaviors they had improved progressively.

\section{Analysis}

This section reports on (i) the students' pre and post attitudes towards videotaping their first speech delivery, and (ii) the students' perceived impact of videotaping on their public speaking skill development over the course of the semester, all from the students' perspective.

\section{Students' Attitudes towards Videotaping their Speeches in the Classroom The Survey}

In order to gather data about the students' attitudes towards videotaping their first speech in class, the researcher administered pre and post surveys consisting of two questions each, including one open-ended question. Each two questions investigated the students' attitude towards video recording (i.e. positive, neutral, negative) and the reasons behind their attitude, or change of attitude in the case of post recording.

The students' responses to the questions whether they would agree to be videotaped in class while delivering their first speech in front of an audience, and if they had changed their perception after the recording took place are presented in table 1.

Table 1: Students' Pre and Post Attitude towards Videotaping Their First Speech in Class

\begin{tabular}{ccc}
\hline Students' Attitude & Pre-Video Recording & Post-Video Recording \\
\hline Positive & 4 & 15 \\
Neutral & 3 & 2 \\
Negative & 13 & 3 \\
Total & 20 & 20 \\
\hline
\end{tabular}


Surprisingly, and as shown in table 1, most students (65\%) had an apprehension towards videotaping their first speech performance in class. In fact, the students' first attitude towards videotaping ranged from, and using the students' own words, 'neutral', 'skeptical', 'afraid', 'shy', 'stressed', 'anxious', to 'excited', and 'happy'. Overall, most students who had mixed feelings about videotaping their first speech related their feelings to the fact that this technique "was new to them and [they] had not done it before", or they were anxious about their physical appearance and thought they "would look awful", or they were just nervous about "standing in front of an audience". Overall, only five students (25\%) expressed their concern for standing in front of their classmates, while the others' (50\%) initial negative attitude was mainly due to the fact that they were "shy", had "no past experience in public speaking" and were, therefore, "not confident" enough they would do a good job. After the speech recording took place in week three, the researcher provided the students with their own copy of the recorded speech, and to the researcher's delight, most students $(75 \%)$ changed their attitude and viewed the technology use in the classroom more positively. Table 2 presents more information about the students' change in their perception.

Table 2: Samples of Students' Responses about Attitude Change towards Videotaping

Student Attitude Before $1^{\text {st }}$ Speech Delivery

$$
\begin{aligned}
& \text { I am skeptical and I don't understand the } \\
& \text { need of videotaping my speech. }
\end{aligned}
$$

I am afraid because this is the first time in my life I would be videotaped delivering a speech, but I feel excited at the same time.

To be honest, I am quite happy particularly because my mother always tells me to videotape my presentations so that she can watch me delivering a speech in front of an audience.
Not very happy with it. I am shy! I have no positive or negative attitude towards videotaping. I am neutral. I am anxious to present my speech in front of my classmates. When I heard that I will be videotaped, the stress and nervousness increased since it is going to be the first time that I get videotaped in public and in class.
Attitude After $1^{\text {st }}$ Speech Delivery

When I got to see my first video, I was surprised when I paid attention to some aspects of my performance I was not aware of before. It really showed me what others were seeing and what I couldn't see.

My first reaction when I watched the video was laughing at myself. It was weird. I noticed my tone was monotonous, but overall it was good to watch myself performing in front of my friends.

I had initially no negative attitude towards this practice, for I did not really care about the camera as much as I cared about the audience. Anyway, I was amazed :) It was good re-watching myself delivering a speech. Very useful!

I felt ok. Interesting experience. After watching myself delivering my speech, I really enjoyed this technique.

My attitude changed after the first speech. Even if I was really anxious about that at the beginning, now I can see the importance of videotaping our speeches. 

awful.

As illustrated, most students who had a neutral or negative initial attitude towards videotaping their first speech changed their attitude completely after watching the video. When asked about how they felt after watching their first speech, some students said that watching themselves "felt weird", while it was "a pleasant experience" to many, and quite "useful" and "interesting", since it helped them become more aware of their "performance" and "body language".

It is worth noting here that this positive change in the students' attitude made it possible for the current research to be conducted, because without a positive attitude towards the technology, the researcher could not possibly consider collecting more data (i.e. videotaping speeches) during the semester, especially that the main goal of this research was to investigate the students' perceptions of and attitudes towards videotaping as a teaching tool.

\section{Students' Perceptions of the Impact of Videotaping on Their Public Speaking Competence The Reflective Essay}

In the reflective essay, the students were required to reflect on their public speaking experience over the course of the semester and explain if and to what extent videotaping had an impact on their public speaking skills development. To do so, they were required to follow three steps: (i) watch the three videotaped speeches and state if they had improved their public speaking skills as they moved from one speech to another, and highlight the skills improved; (ii) explain how videotaping had in fact contributed to this improvement; and (iii) set new goals for the next speech if they were to give a fourth one tomorrow.

\section{Perceived public speaking skills improvement across the three speeches}

The students' reflections revealed that all students watched their videotaped speeches during the semester, and most of them reported making improvements in the following public speaking skills: Content, followed by non-verbal communication, verbal communication, then organization and language. In addition, eighteen students $(90 \%)$ stated that this improvement played a major role in developing self-confidence. 
Table 3: Students' Perceived Improved Skills

\begin{tabular}{cc}
\hline Improved Skills & Student Number \\
\hline Content & 17 \\
Nonverbal Communication & 16 \\
Verbal Communication & 16 \\
Organization & 15 \\
Language & 15 \\
\hline
\end{tabular}

A detailed account of the acquired skills in each category and their respective percentage of occurrence are presented in the next sub-sections.

\section{Content}

As far as speech preparation is concerned, the students reported improvement in meeting the speeches' requirements at the level of the introduction, the body, and the conclusion. The majority (85\%) said they improved in using good 'attention grabbers', 'establishing credibility', and stating a clear 'central idea'. At the level of the body, $80 \%$ of the students learned how to 'refer to sources' to support the main ideas, and $75 \%$ reported 'effective use of visuals'. As for the conclusion, they learned 'how to go back to the introduction without using repetition'. Some students $(70 \%)$ also referred to progressively improving their 'interaction with the audience members' using different techniques, such as stressing the 'you', using humor, and making them more "engaged" in the speech.

\section{Delivery}

With regard to speech delivery, $85 \%$ of the students reported improving their 'posture', 'eye contact', 'voice', 'tone', 'gestures', and 'facial expressions'. $50 \%$ said they adopted a conversational style by speech\#2, and started taking their time to breathe naturally, and could even hear themselves articulating the words' endings quite clearly, compared to speech \#1 where they were speaking fast, swallowed many words, and used many gap fillers when they forgot part of their speech, mainly due to memorization. Memorization is a bad habit that as many students as $80 \%$ reported "bringing with [them] to college from Moroccan high schools", and that they "gradually learned to get rid of when [they] started using note cards. Respecting allotted time set by the professor is another crucial point that $75 \%$ said were "happy and proud they eventually managed to handle" reasonably in their third speech.

\section{Organization}

For the structure and organization of their speeches, $85 \%$ of the students reported improving in writing 'a well-structured outline' for each speech genre, following the samples studied in class, as well as using 'good 
and clear transitions' between the main parts to 'guide the audience'. As for their understanding of different organizational patterns to be used in each speech genre, $90 \%$ reported they knew the difference between different types of organizational patterns in the informative speech, like topical, chronological, and spatial; however, $15 \%$ said they found it difficult to follow Monroe's motivated sequence, and $10 \%$ got sometimes confused when using comparative advantages, but they said the problem - solution order and problem - cause - solution were the easiest to follow in the persuasive speech.

\section{Language}

As for their language use, many students reported different language issues encountered mainly in speech\#1. 30\% of the students said when they watched their recorded speech, they could detect some 'mispronounced words' due to French (L2) influence. 12\% realized their articulation was not clear because of 'mumbling'. About 15\% reported 'word repetition' and 'vocalized pauses' used as gap fillers because they had no word alternatives. The students reported they paid more attention to their language in subsequent speeches and made progressive improvement.

\section{Confidence}

Regarding the students' confidence while standing in front of an audience to deliver their speech, the students reported that progressively, as they moved from one speech to another, they felt 'more confident'. $89 \%$ of the students explained that by speech\#2 they were "no more afraid to go on stage and deliver [their] speech in front of classmates", and they were fully "aware of [their] strengths and weaknesses and how to improve them". The 'teacher's feedback' and 'class discussion' following each speech delivery made them understand they were "not alone in the experience", and helped them believe they could achieve their set goals. In addition to "the positive class environment", the fact that they could "see real improvement in the videos", which was witnessed by their classmates too, made them "develop self-confidence" and become "more positive about the course".

\section{Perceived impact of videotaping on improved public speaking skills}

As for the impact of videotaping on the students' public speaking skills, all students stated that videotaping played a "major role" in their improvement at many levels. First, the students explained that after each speech delivery they were always "excited" and "eager" to "watch [their] performance". Most of them stated that it was an "enjoyable experience" to watch themselves, and "live the moment of [their] real speech delivery in the classroom”. 
Some even said they "used headphones to listen to [their] voice" in order to check if their tone was as "monotonous" as some peers claimed, or "to enjoy listening to the musicality" in their voice that the audience liked. Others were curious "to see or sense the charisma and strong presence" that the professor liked about them. Many students said they could not believe the positive feedback they received in class, simply because they "never before paid attention to [their] voice, gestures, or body language", so they needed to see it or hear it in order to believe it.

In addition, watching their performance also served the students to "avoid past mistakes". Videotaping enabled the students to "clearly see" and identify their "strengths and weaknesses"; weaknesses they targeted as areas they needed to improve through practice before the next speech delivery.

The participants reported that although the professor "provided feedback" after their speech delivery, they "needed to see and judge" their own performance, and evaluate to what extent they had "improved compared to the previous speech". Thus, videotaping (i) enabled the students to enjoy the experience of watching their performance for the first time in their life, (ii) made them aware of different aspects of their speech delivery (non-verbal and verbal), (iii) contributed to developing their self-confidence, (iv) enabled them to critique themselves (identifying strengths and weaknesses), and (v) helped them set specific goals for the next speech.

Selected excerpts from the students' own reflections on the impact of videotaping on public speaking skills' development across their three videotaped speeches are illustrated in table 4.

Table 4: Students' Reflections on Impact of Videotaping on Improved Skills across the

Student

Self-introduction Speech

In the $1^{\text {st }}$ speech I was very nervous. My main weakness is that there is no order in the speech; I just went from idea to another. My speech rate was too fast. I should improve!

Three Speeches

Informative Speech Thanks to the video I realized I made a lot of progress! I broke the glass that was between me and the audience. My strengths consist in my posture: I stopped moving back and forth. Reference to the sources: I gave them in the right time and in a professional way: Topic: I mastered the topic, so I talked more confidently. This video made me happy to see my improvement. Now I know exactly what I need to focus on for the next speech.

By watching my second speech I can confirm that
Persuasive Speech

This speech was the best! It's like a President of a country who is used to his job. I was more confident, I talked in a confident way. I improved the eye contact, I' $\mathrm{m}$ not afraid anymore about seeing the others watching me now; it gives me more confidence. I improved also the gestures, tone and especially establishing credibility using the sources that I cited during the speech. This speech was more professional I would say.

I believe this video is the best, compared to the two nervous. Yet, I can clearly 
see that my strengths reside in the fact that I clearly articulate. I never heard myself before, so I didn't know this. Also, I use wellstructured sentences that thoroughly illustrate the points I want my audience to grasp. I also maintain good eye-contact, and use $\underline{\text { a }}$ conversational style, and interact with my audience (I nod my head and look them in the eye to make my points more casual and relatable). My weaknesses however can be seen in my weak memory (I sometimes slow down and struggle using gap fillers in order to remember an expression or idea I was planning on saying). So based on this video I believe next time I need to focus on organization and timing.
I definitely made progress in the transition from my first speech to my second speech. For instance, I improved my delivery techniques by integrating many logical transitions in my speech in order to make my points clearer. My strengths in this speech can be seen in the amount of precise and detailed information I provided my audience with, such as the author's date and place of birth, or his cultural and political background. Nevertheless, I had one major weakness which was going over-time ( 8 minutes). I need to sort it out in the persuasive speech. previous ones. I didn't leave out any details, and I respected all the speech requirements. The aspects of my delivery that I improved are: eye-contact, voice, gestures, posture, and most importantly time. The aspects of my speech that I improved are: the attention grabber, emotional appeal, and visuals. I' $m$ proud!

\section{Setting goals for the next speech}

All 20 students reported 1 to 3 aspects of their speech they would like to improve if they were to deliver a fourth speech tomorrow. Most comments pertained to speech content, followed by organization and allotted time. Considering that by the end of the semester all students reported major improvements in terms of their delivery, namely body language, eye contact, voice, and speech rate, none of them referred to this aspect of their speech. Regarding content and organization, for instance student $\{8\}$ said "If I were to give a speech tomorrow, I would work harder on enhancing referring to sources and speech organization. Throughout my speech, I sometimes forgot to orally refer to my sources when providing the audience with evidence or information." Another student $\{13\}$ said; "I would definitely work on structure. My organization wasn't always quite clear towards the end of my speech. This resulted in a weak conclusion". Finally, for timing, student $\{10\}$ stated "time management is a challenge to me because I tend to forget it and keep giving examples. Also, I would improve my transition from one subject to another". As demonstrated, although the students reported major public speaking skills' improvement during the process of their three speeches' preparation and delivery, they identified different areas they would still like to improve should they give a fourth speech tomorrow. 


\section{Discussion}

The purpose of this study was to determine whether a combination of videotaping and self-reflection assessment essays had a major impact on college students' public speaking skills development as perceived by the students. The pre and post videotaping surveys revealed that most participants $(75 \%)$ who had neutral or skeptical attitudes towards being videotaped while delivering their first speech in front an audience adopted a more positive attitude after watching their first performance.

Students' reflective essays revealed that all students without exception $(100 \%)$ reported that videotaping had a major role and impact on their public speaking skills' development as they moved from one speech to another. Students' improvements were clearly demonstrated at the levels of content, non-verbal communication, verbal communication, followed by organization and language, which in turn contributed largely to developing most students' (90\%) self-confidence, confirming findings from previous studies (Bourhis \& Allen, 1998; Guo, 2013; Wilhelm, 2014).

Overall, videotaping public speaking speeches proved to be quite an enjoyable experience to EFL students, and a very useful, accurate, and reliable tool to double check strengths and/or weaknesses as identified and highlighted in teacher feedback, and confirmed by the student speakers themselves. In addition, students found videotaping very effective in assessing individual improvement, and for setting goals across the speeches to achieve major public speaking skills development. In fact, some students even reported that thanks to videotaping they enjoyed the course more.

\section{Conclusion}

Considering that all participants had no past experience in public speaking, most of them were reluctant to have a camera focused on them while standing in front of an audience. After watching their initial performance, all students with no exception adopted a more positive and collaborative attitude.

The combination of videotaping and self-reflection assessment essays resulted in major improvement in the students' public speaking skills. Watching their performance enabled the students to (i) better understand their abilities, (ii) set new goals for the next speech delivery, (iii) and have a better preparation since they clearly understood the teacher's expectations, and they could physically see where they went wrong, what they needed to fix, and how to fix it.

\section{Limitations}

In this study, the researcher involved one section only of twenty freshman students due to the fact that the process of videotaping the students' sixty speeches and waiting for the technician to download the speeches on a 
computer, then provide the researcher with copies of the recorded speeches, and eventually provide each student with his / her own copy to retain was time consuming. Therefore, involving more students across the disciplines should yield more data for further analysis.

\section{Recommendations and Future Research}

Based on the students' perceptions of video recording as a useful and effective teaching tool in the public speaking course, it is recommended to use this technology in the classroom to ensure effective learning and public speaking skills' improvement and development. As stated by the students themselves and clearly demonstrated in the analysis part, thanks to video recording students could keep copies of their speeches and watch their performance many times, and analyze them thoroughly in preparation for future speech delivery, which enabled the students to enhance their skill development and become independent learners. Although they were provided with feedback in the classroom, the students enjoyed viewing their own speech, identifying their strengths and weaknesses, and setting individual goals for future performance in order to correct past mistakes. Here comes the role and the importance of self-reflection essays that students could not possibly produce in an accurate and successful manner unless they watched their performance again and again.

Finally, videotaping three or four speeches for the whole class could be a long, hectic, and time consuming process, unless technical facilities and support are available; but given the amazing results and major public speaking skills improvement as reported by the students, it is worth the effort for the outcome is rewarding.

As for research, using a larger sample size of EFL students should be considered to collect more data. Also, investigating perceptions and attitudes of both the learners and instructors would shed more light on the subject. Finally, studying the correlation between technology and specific skills would be interesting to explore both quantitatively and qualitatively.

\section{References:}

1. Boling, E. C. (2008). Learning from teachers' conceptions of technology integration: What do blogs, instant messages, and 3D chat rooms have to do with it? Research in the Teaching of English, 43(1), 74-100.

2. Bourhis, J., \& Allen, M. (1998). The role of videotaped feedback in the instruction of public speaking: A quantitative synthesis of published empirical research. Communication Research Reports, 15 (3), 256-261. DOI: 10.1080/08824099809362121 
3. Daniel, A. (1983). Communication Apprehension and the Use of Video-Tapes. Paper presented at the Annual Meeting of the Speech Communication Association (Washington, DC, November 10-13, 1983).

4. De Grez, L., Valcke, M., \& Roozen, I. (2012). How effective are self and peer assessment of oral presentation skills compared to teachers' assessments? Active Learning in Higher Education, 13 (2), 129-142. DOI: 10.1177/1469787412441284

5. Deihl, E. R., Breen, M. P., \& Larson, C.N. (1970). The effects of teacher comment and television video tape playback on the frequency of non-fluency in beginning speech students. Speech Teacher, 19, 185189.

6. Do, T. Q. T., \& Dang, T. C. T. (2014). Impacts of video-recorded feedback in public speaking classes: An empirical study. Language Education in Asia, 5(1), 28-45. http://dx.DOI.org/10.5746/LEiA/14/V5/I1/A04/Do_Dang

7. Frandsen, K. D., Larson, C. E., \& Knapp, M. L. (1968). Simulation and self-confrontation in interpersonal Communication. Educational Broadcasting Review, 2, 18-23.

8. Fukkink, R. G., Trienekens, N., Kramer, L. J. C. (2011). Video feedback in education and training: Putting learning in the picture. Educational Psychological Review, 23, 45-63. DOI 10.1007/s10648010-9144-5

9. Ginsburg, C. (1956). A new magnetic video recording system. Journal of Society of Motion Picture and Television, 65, 302-304.

10. Guo, R X. (2013). The use of video recordings as an effective tool to improve presentation skills. Polyglossia, 24, 92-101.

11. Hinton, J. S., and M. W. Kramer. 1998. "The Impact of Self-directed Videotape Feedback on Students' Self-reported Levels of Communication Competence and Apprehension." Communication Education 47 (2): 151-161. doi:10.1080/03634529809379119.

12. Jensen, K. K. \& Harris, V. (1999). The public speaking portfolio. Communication Education, 48(3), 211-227.

13. Maloney, S., Paynter, S., Storr, M. \& Morgan, P. (2013). Implementing student self-video of performance. The Clinical Teacher, 10, 323-327.

14. McCroskey, J. C., \& Lashbrook, W. B. (1970). The effect of various methods of employing video-taped television playback in a course in public speaking. Speech Teacher, 19, 199-205.

15. Mills, G. E., \& Pace, R. W. (1989). What effects do practice and video feedback have on the development of interpersonal communication skills? The Journal of Business Communication 26(2), 159-179. 
16. Mulac, A. (1974). Effects of three feedback conditions employing videotape and audiotape on acquired speech skill. Speech Monographs, 41, 205-214

17. Nair, A. G., Kamal, S., Dave, T. V., Mishra, K., Reddy, H. S., Della Rocca, D., Della Rocca, R., Andron, A. \& Jain, V. (2015). Surgeon point-of-view recording: Using a high-definition head-mounted video camera in the operating room. Indian Journal of Ophthalmology, 63, 771-4. DOI: 10.4103/0301-4738.171506.

18. Ozcakar, N., Mevsim, V., Guldal, D., Gunvar, T., Yildirim, E., Sisli, Z. \& Semin, I. (2009). Is the use of videotape recording superior to verbal feedback alone in the teaching of clinical skills? BMC Public Health, 9, 474-478. DOI:10.1186/1471-2458-9-474

19. Pinter, E. B., East, A., \& Thrush, N. (2015). Effects of a videofeedback intervention on teachers' use of praise. Education and Treatment of Children, 38(4), 451-472.

20. Porter, D. \& King, G. (1972).The use of video-tape equipment in improving oral interpretation performance. Speech Teacher, 99-106.

21. Quigley, B. L. \& Nyquist, J. D. (1992). Using video technology to provide feedback to students in performance courses. Communication Education, 41 (3), 324-334. DOI: 10.1080/03634529209378892

22. Ramos, A. R., Esslinger, K., \& Pyle, E. (2015). The effects of field experience on delivery of feedback. The Physical Educator, 72, 278287.

23. Thu, D. T. Q \& Tu, D. T. C. (2012). Videotaped Feedback in Public Speaking Courses: Potential Application to Vietnamese Pedagogical Setting. Journal of Science, 70(1), 237-245.

24. Wilhelm, T. (2014). Effective Use of Multi-faceted Video Feedback for ESL Speech/Presentation Course. Humanizing Language Teaching, 16 (1). ISSN 1755-9715.

25. Woolley, T. R. (1968). Potential utility of VTR as an auxiliary device. Speech Teacher, 9, 135-139. 


\section{Appendix}

Survey on the Use of Videotaping in the Public Speaking Classroom

\section{Pre-videotaping questions}

1. Would you agree to be video-taped during your next speech delivery?

a. Yes, I would like to.

b. I do not know.

c. No. I do not want to be video-taped.

2. If you circled (c) in question 1, explain the reasons behind you choice.

\section{Post-videotaping questions}

1. Now that you have been videotaped during your first in-class speech delivery, how do you feel about the experience?

a. Yes, I liked it.

b. I do not know.

c. No, I did not like it.

2. Please explain the reasons behind your choice / or change in your choice. 